\title{
Editorial
}

\section{A Política Nacional de Inovação e as Instituições de Ciência e Tecnologia (ICTs)}

É possível obter um forte impacto pela Política de Inovação das ICTs na organização, implementação e execução das políticas federais, setoriais, regionais, estaduais ou municipais com o intuito de dinamizar o Sistema Nacional de CT\&I (SNCTI)? Como a prospecção tecnológica pode dar suporte à implementação e à consolidação das políticas de inovação?

Antes de responder a essas perguntas, é importante percorrer brevemente a trajetória do framework que enquadra os Núcleos de Inovação Tecnológica (NITs) e a Política de Inovação das ICTs.

Após a regulamentação da Lei de Inovação, em 2005, houve uma crescente aproximação entre as ICTs e as empresas, provocando mudanças importantes nos modelos institucionais e gerenciais das ICTs. Mas, com relação à Política Institucional de Inovação em si, a primeira versão da Lei foi vaga e resultou em dificuldades para sua institucionalização, tendo ficado restrita a implementação dos NITs para a gestão de propriedade intelectual e a transferência de tecnologia ${ }^{1}$.

Na reforma da Lei n. 10.973, materializada pela Lei n. 13.243, de 2016, a equipe técnica e jurídica do Ministério da Ciência, Tecnologia e Inovações (MCTI), com o propósito de aperfeiçoar o empreendedorismo tecnológico inovador das ICTs, revisou, no Capítulo II da Lei n. 10.973, os artigos 16, 17 e 18, que tratam, respectivamente, dos Núcleos de Inovação Tecnológica (NIT), das informações ao MCTI e das providências de organização orçamentária e das receitas de inovação para suportar a política de inovação na ICT. Nessa ação, introduziu-se o artigo 15A, que estabelece as diretrizes de implementação e de definição de objetivos estratégicos para a política de inovação da ICT, considerando a missão da instituição. Nessa orientação, a ICT estabelece as diretrizes para organizar as instâncias de governança e de coordenação e ordena os instrumentos gerenciais e normativos para estruturar, de forma integrada, os processos de geração de conhecimento e de inovação em parceria com o ambiente produtivo, considerando as políticas, os instrumentos, os recursos e os atores do desenvolvimento local, regional e nacional.

Mais especificamente, a política de inovação da ICT deve reforçar as interfaces e as conexões entre os instrumentos de empreendedorismo de base tecnológica, com a transferência de tecnologia e a gestão da propriedade intelectual, alinhado-os com a capacitação institucional bem mais ampla que a atuação gestora do NIT. Sendo que este também teve sua capacidade

\footnotetext{
${ }^{1}$ Além das dificuldades, a análise das estatísticas consolidadas nos relatórios anuais do Formict deixa claro um baixo desempenho das ICTs na consolidação de suas Políticas de Inovação, expressa em termos de pedidos de patentes, e, sobretudo, em parcerias de P\&D, contratos de transferência de tecnologia e empreendedorismo inovador. Esse quadro serviu de base para propor a revisão do tema na reforma da Lei de Inovação, editada com a Lei n. 13.243 , de 2016 - e, a partir dele, propôs-se agregar o artigo 15-A para melhorar a didática e a autoaplicabilidade do dispositivo "Política de Inovação da ICT". Além disso, nesse artigo, consta que a política não é a mera instituição de alguns de seus instrumentos, como o NIT e os regulamentos de propriedade intelectual, coube ao dispositivo orientar diretrizes estruturantes e estratégicas para a formulação da Política de Inovação nas ICTs.
} 
ampliada pela possibilidade de personalidade jurídica própria para fortalecer sua ação executiva e de suporte à gestão.

Assim, no framework desenhado pelo cenário normativo da Lei n. 10.973, reformada pela Lei n. 13.243, de 2016, a rota principal de desenvolvimento institucional das ICTs é uma política de inovação mais agressiva, capaz de usar as alianças estratégicas, as encomendas tecnológicas, a constituição de fundos de investimento e a participação no capital social de empresas, com o suporte de NITs e fundações de apoio mais fortes, bem como o compartilhamento mais eficaz de infraestruturas, recursos humanos e capital intelectual para responder com mais musculatura aos desafios de desenvolvimento de P\&D estratégica e de fronteira, transferência de tecnologias e conhecimentos e a geração de inovação, junto com os setores produtivos na consolidação de ecossistemas de inovação. Ou seja, o quadro de referência normativo suporta que a forma mais competitiva para as ICTs organizarem as suas respectivas políticas de inovação é elaborar e implementar a gestão estratégica da PD\&I, com base no modelo triple helice, mas expandindo seus desdobramentos até a quinta hélice na construção e na consolidação de ecossistemas locais de inovação. Nessa direção, tendo o suporte normativo e jurídico para estabelecer também parcerias com agências, universidades e com empresas para realizar estratégias de internacionalização de P\&D, transferência de tecnologia e inovação.

Estima-se que, ao consolidar as políticas institucionais de inovação das ICTs e subsidiar a superação de seus gargalos de gestão, é possível obter impactos no Sistema Nacional de CT\&I, como: 1) a aceleração dos processos de transferência de tecnologia e de conhecimentos; 2) um aumento do volume de alianças estratégicas, parcerias e contratos em PD\&I; 3) um reposicionamento das carteiras de projetos institucionais de pesquisa, visando a aumentar a relevância dos fluxos de transferência de conhecimentos; 4) a reorientação das missões das ICTs, buscando competitividade institucional na atuação sobre o desenvolvimento local e regional; e 4) um maior arrecadamento de recursos e de incentivos fiscais para a PD\&I nas ICTs.

Para que haja a materialização desse cenário normativo traçado, o caminho lógico é o de fortalecer e de avançar as articulações institucionais necessárias para desenvolver as ações de regulamentação e promover o uso inteligente dos instrumentos do Novo Marco Legal de CT\&I. Entretanto, sem dúvida, isso ainda precisará ser melhor entendido e consolidado em nível de governança e de coordenação intra e entre governos e ICTs para a Política de Inovação dessas instituições efetivamente dinamizar o SNCTI. A evidência da falha de governo no tema pode ser constatada no exercício de tomar como referência o alinhamento da Política de Inovação de uma ICT, com as prioridades da Política Nacional de CT\&I, em acordo com o artigo 15-A da Lei n. 10.973/2004.

Ao analisar a recente Política Nacional de Inovação (PNI), editada pelo Decreto n. 10.534, de outubro de 2020, pergunta-se: quais são as prioridades estabelecidas para orientar as PD\&Is das ICTs? A PNI definiu princípios, eixos de implementação e objetivos, mas, quanto às prioridades, houve uma delegação de competência dessa definição para a Câmara de Inovação criada pelo Decreto e integrada por 11 ministros - que, talvez, possa instituir tais prioridades na Estratégia Nacional de Inovação ou nos Planos Setoriais que irão compor a Política. Entretanto, a Estratégia Nacional de Inovação, já em consulta pública, está estruturada em Diretrizes de Implementação dos Eixos definidos na PNI e não traz a definição de prioridades. Além disso, provavelmente a aprovação dessas prioridades deverá ter que ser realizada em articulação com 
o Conselho Nacional de Ciência e Tecnologia (CCT), instituído pela Lei n. 9.257, de 1996. Articulação esta que também não teve sua forma definida no Decreto.

Em relação à coordenação nacional, para a qual também seria fundamental essa definição do alinhamento com os entes subnacionais, o artigo $1^{\circ}$ do Decreto apenas aponta esse alinhamento como a finalidade da Politica - "estabelecer mecanismos de cooperação entre os Estados, o Distrito Federal e os Municípios para promover o alinhamento das iniciativas e das políticas federais de fomento à inovação com as iniciativas e as políticas formuladas e implementadas pelos outros entes federativos". Todavia, pelo limite de competência sobre a Administração Federal, o Decreto rege em seu artigo 15 que "[...] a colaboração dos Estados, do Distrito Federal e dos Municípios com a Política Nacional de Inovação se dará por meio de adesão voluntária, na forma definida em ato do Ministro de Estado da Ciência, Tecnologia e Inovações".

Ou seja, a PNI como resposta do governo às avaliações e às recomendações do Acordão TCU 1237/2019, apesar da celeridade em sua formulação, não respondeu satisfatoriamente às falhas de coordenação horizontal e vertical do SNCTI e nem supre a recomendação de definição de prioridades. Claro que, apesar de haver a necessidade de mais tempo para articular no Congresso um Projeto de Lei, teria sido mais coerente e robusto ter seguido o caminho apontado pelo artigo 219B da Constituição para instituir a Política e o Sistema Nacional de CTI via Lei Complementar.

Sem contar que, para além do apontamento das prioridades como elemento-chave de coordenação do SNCTI e das políticas de inovação das ICTs, entende-se que essas prioridades seriam fundamentais para o alinhamento e o acoplamento a serem construídos com a Estratégia Nacional de Propriedade Intelectual (ENPI) que se está formulando. A definição clara de áreas e de setores tecnológicos a serem priorizados para a inovação nos sistemas produtivos e de serviços balizaria estratégias reais no campo da propriedade intelectual para a apropriação, o compartilhamento, a transferência e a difusão de conhecimentos e de tecnologias. Então, formular um campo estratégico para otimizar a criação, a apropriação e a difusão de inovações não deve ser confundido com a proteção do agente inovador.

Tais prioridades também poderiam balizar o alinhamento da PNI com a Política de Desenvolvimento Regional (PNDR) e as estratégias de especialização inteligente de regiões e de territórios - construindo bases para direcionar a política de inovação das ICTs. Esses alinhamentos são importantes não apenas para dar orientação, consistência e coerência às Políticas Institucionais, como também para subsidiar o uso dos instrumentos dessas políticas e a captação de recursos para projetos e empreendimentos técnico-científicos estratégicos.

É diante desses desafios, que parecem quase intransponíveis, no campo da formulação e da coordenação das Políticas (Nacionais, Regionais, Estaduais, Municipais, Institucionais, e outras), que este volume da Cadernos de Prospecção nos brinda com mais estudos e conhecimentos de como a prospecção tecnológica e a propriedade intelectual podem dar suporte a processos de transferência de tecnologia, inovação e desenvolvimento. Dessa forma, este veículo, junto com o Profnit, vem clareando caminhos táticos, atalhos e balizas importantes para formular, implementar e consolidar as Políticas e as Estratégias de Inovação.

Por fim, diante do exposto, é importante reconhecer como as publicações em Revistas Nacionais, gratuitas e de acesso aberto vêm contribuindo para fortalecer o impacto efetivo da 
produção acadêmica (científica, técnica e tecnológica) sobre comunidades e ecossistemas de inovação no país.

Nesta Edição, são publicados artigos de 83 autores, afiliados a 37 organizações dos setores acadêmico, empresarial e governamental, distribuídas em cinco regiões do Brasil e no Distrito Federal.

Edilson da Silva Pedro

Profnit UnB/Analista em C\&T no MCTI 